\title{
Harpócrates y la iconografía del poder imperial en las acuñaciones nomaicas de Trajano y Antonino Pío
}

\author{
Harpócrates and the iconography of the imperial power in the \\ coinages nomaicas of Trajan and Antoninus Pius
}

\author{
DOMINGo SAURA ZORRILLA*
}

\begin{abstract}
RESUMEN
Egipto presenta en época de los emperadores Antoninos unas series monetales excepcionales de tipo provincial, o mejor "subprovincial», pues están batidas en los nomos o distritos egipcios, apareciendo

sus nombres geográficos escritos en los reversos; y junto a las leyendas se muestran

las imágenes de las divinidades tutelares,

Isis, Horus-Harpócrates, etc. Así pues, anversos y reversos se complementan en las monedas ofreciendo una iconografía religiosa local egipcia en apoyo de la ideología imperial romana, a la que se adapta, y a la que se integra en las acuñaciones de la primera mitad del siglo II d.C. El presente trabajo estudia y comenta a modo de ejemplo la iconografía de algunas de estas emisiones, concretamente las que se centran en la figura de Harpócrates, y como se complementan con el ejercicio propagandístico llevado a cabo en Egipto por los principales emperadores del siglo ॥l d.C.
\end{abstract}

PALABRAS CLAVE:

Isis, Horus, Harpócrates, Iconografía, Egipto, Numismatica.

\begin{abstract}
In the Antonine Period Egypt presents an exceptional provincial or rather subprovincial coinage, as they were made in the so called nomes or Egyptian districts. On their reverses we find the geographical names and, together with the legends, images from the provincial gods such as Isis, Horus-Harpokrates, etc. Hence, obverses and reverses complement each other offering an Egyptian, local and religious iconography supporting imperial Roman ideology, to which it adapts and integrates on the coins minted in the first half of the second century $A D$. Here we study and comment as an example the iconography on some of these coins, especially those focused on the figure of Harpokrates, and how they served as a complement to the propaganda exercise carried out by the main emperors in the second century $A D$ in Egypt.
\end{abstract}

KEYWORDS:

Isis, Horus, Harpokrates, Iconography, Egypt, Coinage.

* Universidad de Murcia. 
La historia nos muestra, así como el presente más inmediato, el papel tan fundamental que juega la religión y el uso que se hace de ella cuando lo que se pretende es el dominio de las masas. Actúa como una suerte de magia inductiva, que al igual que la magia más convencional, se vale de diferentes medios para conseguir un mismo fin: el control, el poder. A través de la religión se proclaman guerras, las fronteras cambian y se doma al ser humano. Si bien en la magia el cliente, que lo puede ser cualquiera, es un agente activo, obteniendo él mismo pequeñas dosis de poder, a través de la religión son unos pocos los que se ven inmensamente beneficiados por recaer solamente en ellos el poder casi absoluto, siendo la gran masa de seguidores agentes pasivos, que acaban acometiendo lo que los grandes líderes desean. De ahí que actúe como una droga, como un opiáceo a la manera de Nietzsche, como un moldeador de la voluntad por el que se puede convencer a todo un país de que la diferencia entre el bien y el mal es esta y no otra.

Religión y poder van pues íntimamente ligados en el discurrir de la antigüedad, es difícil entender una sin la otra, y qué mejor medio de control de las masas para un imperio como el romano en el siglo ii d.C., que abarcaba la práctica totalidad de la actual Europa, Turquía, Palestina, Egipto y el norte de África, que valerse de la religión, respetando las tradiciones de los pueblos conquistados, asumiendo multitud de divinidades, y asimilando los emperadores a las diferentes divinidades que también eran conquistadas.

Mi estudio se centrará por tanto en el lugar común para la manifestación religiosa y política que suponen las acuñaciones batidas en los nomos egipcios, ya que en ellas se conjugan lo divino y lo humano con un mismo propósito: mostrar el poder.

La elección de mi franja espacio-temporal no responde a la casualidad, ya que es en la primera mitad del siglo II d.C. donde se producen una serie de emisiones con base en Alejandría que muestran una particular representación de Harpócrates con su mitad inferior en forma de cocodrilo. Una aproximación iconográfica e iconológica a esta figura, intentando encontrar paralelismos en otros formatos (relieves, estelas, gemas, etc.) y en diferentes fuentes literarias se hace pues necesaria. Asimismo, estableceré las relaciones entre la figura de ese niño-dios y el propio perfil que se fija el emperador representado en la acuñación cuando se hace acompañar de tan curioso dios.

En el último apartado destacaré el sentido de la moneda como vehículo de propaganda política, así como las particularidades que ofrece al poder reunir en tan poco espacio pero de forma tan efectiva las representaciones del poder religioso y civil, asimilándose éstos y dando lugar a nuevas interpretaciones. 


\section{ESTRATEGIAS PROPAGANDÍSTICAS IMPERIALES}

Las monedas de los nomos egipcios constituyen una serie de emisiones monetales acuñadas en Alejandría ${ }^{1}$, centro administrativo romano en Egipto ${ }^{2}$. Esta ciudad estaba bajo gobierno directo del emperador y ocupó una posición excepcional como el mayor centro comercial de Egipto y uno de los principales del Mediterráneo ${ }^{3}$. Fue un caso particular el de su romanización, ya que en Alejandría y Egipto este proceso se vio mermado por la antigua y profunda tradición que imperaba en la zona. Roma era apoyada, entre otras cosas, por el elemento helenístico que dejaron Alejandro y la dinastía ptolemaica, más afín con la cultura romana. De esta forma, Alejandría gozó de una libertad en su desarrollo interno que no tenía parangón en todo el imperio, pudiendo mantener sus tradiciones y costumbres, siempre y cuando mantuviera intacta su lealtad al emperador, divinizado desde la época de Augusto. Esto explica por tanto el hecho de que poseyera una ceca propia. Ceca en la que no sólo se emitían acuñaciones para la región que la ciudad ocupaba, sino que de ella también salían las acuñaciones nomaicas, aquéllas en las que se hacía mención especial a las diferentes distritos en las que se dividía el territorio de Egipto.

Estas acuñaciones nomaicas formaban por tanto parte del sistema de propaganda política llevado a cabo en las diferentes metrópolis egipcias por los prefectos romanos. En líneas generales se puede decir que en su reverso hacían alusión a los diferentes territorios en que se dividía el país del Nilo4, presentando a la divinidad tutelar de esa zona y la inscripción pertinente. En su anverso aparece la efigie del emperador en curso. Es de destacar que esta serie de acuñaciones sólo remiten a cua-

1 Para el estudio de las monedas alejandrinas me he centrado principalmente en el catálogo de J. G. Milne, Catalogue of Alexandrian coins, Oxford, 1971 (con suplemento de C. M. Kraay). Otros estudios que hacen referencia a estas emisiones son: J. F. Tochon D'Annecy, Recherches historiques et géographiques sur les médailles des nomes ou préfectures de PÉgypte, Paris, 1822; V. Langlois, Numismatique de nomes d'Égypte sous Padministration romaine, Paris, 1852; R. S. Poole, Catalogue of Greek coins, Alexandria and the nomes, Londres, 1892; G. Dattari, Monete Imperiali Greche. Numi Augg. Alexandrini, Vol. I-II, El Cairo, 1901; A. Geissen, Katalog Alexandrinischer Kaisermünzen der Sammlung des Instituts für Altertumskunde der Universität Köln, Vols. I-IV, Colonia, 1974-1983; E. Christiansen, The Roman coins of Alexandria. Quantitative Studies, Aarhus, 1987; Ídem. Coins of Alexandria and the nomes. A supplement to the British Museum Catalogue, Londres, 1991; LIMC VI, V. Tran Tam Tinh, s. v. Harpócrates, pp. 415-445; K. Emmet, Alexandrian Coins, Lodi, 2001; L. Bricault, «Monnaies des nomes au Cabinet des Médailles de la Bibliothèque royale de Belgique», en Revue Belge de Numismatique et de Sigillographie 149 (2003), pp. 43-58.

2 Se ha venido discutiendo a lo largo del siglo xx acerca del lugar de acuñación de estas emisiones nomaicas, ya que se pensaba que cada una había sido producida en la propia región que representaba. Esa posibilidad hoy en día no se refleja y se tiene a Alejandría como único centro emisor, dadas las numerosas coincidencias de estilo y fábrica que presentan. Vid. J. Sheridan, «The nome coins of Alexandria, another look», ANSMN 33 (1988), pp. 107-110.

${ }^{3}$ Cf. Str. 17, 798; Tac. Ann., 2, 59.

${ }^{4}$ El número de nomoi en los que se dividía Egipto viene siendo tema de discusión dado que las fuentes varían, así, Diod. Sic. I, 54, 3 y Str. XVII, I, 3 ofrecen la cifra de 36 nomos en época augustea, a principios del siglo I d.C., mientras que cincuenta años después, en época de Vespasiano, se puede observar en Plin. HN, V, 49-50 que la cifra asciende a 47. Cf. Pap. Oxy. 3362 y J. D. Thomas (ed.), «List of nomes « en Akten des XIII Internationalen Papyrologenkongresses, Marburg, 1971. 
tro emperadores entre finales del siglo I d.C. y la primera mitad del siglo ii d.C., a saber, Domiciano, Trajano, Adriano y Antonino Pío 5 .

En unos casos resulta más obvio el por qué de estas emisiones provinciales, o mejor, «subprovinciales». En el caso del emperador Trajano, como señala Blázquez, su tipología «sigue el sentido propagandístico a través de un lenguaje sencillo y comprensible para todo el mundo" 6 . Abundan en su reinado las emisiones con personificaciones de la Abundantia puestas en relación con niños, como es el caso de Harpócrates y la cornucopia rebosante de frutos que siempre porta sobre su brazo izquierdo. Esto, continúa Blázquez, no haría sino «aludir a la institución de los alimenta»" Trajano, al igual que el resto de los emperadores Antoninos pretende transmitir con las diferentes emisiones nomaicas un mensaje social, de integración recíproca y evidente: Egipto es parte de Roma y Roma es parte de Egipto.

Por otro lado se sitúa Adriano, uno de los pocos emperadores que viajó a Egipto, visitando las diferentes regiones del país y conmemorando su visita en forma de templos, ciudades de nueva planta y diferentes emisiones monetales ${ }^{8}$. En el caso de Adriano existe una fuerte integración de su gobierno con el pensamiento egipcio, dado el talante de su reinado por un lado y su fuerte filohelenismo por otro, produciéndose de esta forma una reconciliación entre Roma y los griegos de Egipto, todo lo cual se vio reflejado de forma lógica en las emisiones monetales, como manera de conmemorar su entrada en el país.

Estos emperadores sabían que lo que más se respetaba en Egipto era el sincrético acervo religioso y su panteón divino regido por dioses milenarios. No resultaba complejo llegar a la conclusión de que el mejor método para controlar ese país de forma efectiva era hacer ver que el nuevo emperador era tan benévolo, divino y poderoso como las mismas divinidades a las que se rendían culto.

Una de las mejores fórmulas para comunicar esa noticia a todos los estratos del pueblo, era aquella que llegaba a todos los estratos del pueblo, es decir, las producciones monetales.

Para llevar hasta su punto más alto este pensamiento, la moneda suponía el soporte perfecto para acercar la figura del emperador a la plebe. Conjugando su imagen con las diferentes divinidades provinciales se aseguraba que la representación del poder llegara a todos los niveles, tanto sociales como geográficos. La estrategia propagandística imperial se basaba en utilizar a los dioses tutelares nomaicos, queridos y respetados por el pueblo, como una suerte de alter ego del mandatario romano. El emperador se "deshumanizaba», "sacralizándose» al emparentarse con el dios, siendo así querido y respetado cual divinidad.

5 Concretamente se producen en el año XI del reinado de Domiciano (91-92), los años XII y XIII de Trajano (108/109 y 109/110), el año XI de Adriano (126/127) y el año VIII de Antonino Pío (144/145).

6 J. M. ${ }^{a}$ Blázquez, Trajano, Barcelona, 2003, pp. 219-225.

7 Ibid. p. 223.

8 B. W. Henderson, The life and Principate of the Emperor Hadrian, Roma, 1968, p. 94. 
La táctica era perfecta: utilizar un soporte material que llegara a todas las capas sociales, como es la moneda, con otro soporte espiritual que actuara sobre la voluntad y el pensamiento de todo un pueblo, es decir, la religión.

Estudiaré a continuación los pormenores de una iconografía muy particular que hace referencia al dios Harpócrates, utilizado en algunas de las emisiones alejandrinas que hacen referencia a uno de los nomos en los que se dividía Egipto, el Menelaita.

\section{EL NIÑO-DIOS COMO MODELO DE PODER: ACUÑACIONES IMPERIALES CON LA REPRESENTACIÓN DE HARPÓCRATES}

Los documentos monetales que hacen referencia a Harpócrates con la mitad inferior de cocodrilo son bastantes escasos, ya que apenas tenemos una docena de ejemplos en lo que a numismática se refiere. La práctica totalidad de ellos se producen en los reinados de Trajano y Antonino Pío, refiriéndose todos ellos al nomo MENELAEITH o Menelaita ${ }^{9}$, ubicado en el Bajo Egipto, en la región de Alejandría, lo que hace ya pensar que esta tipología de Horus-niño se erigía como divinidad tutelar de ese área.

Tomaré como ejemplo para el análisis iconográfico una emisión de la época de Antonino Pío, haciendo extensible, dadas sus fuertes semejanzas, el comentario sobre su descripción y significado al resto de monedas que albergan a este particular Horus-Sobek en su reverso ${ }^{10}$.

Antonino Pío (138-161) ${ }^{11}$, fig. 1.

Dracma; nomo Menelaita; 144/145

Fondo General 4056 de la Biblioteca nacional de Francia.

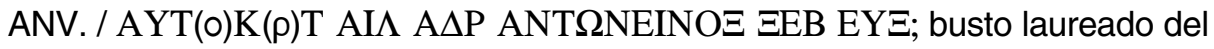
emperador Antonino Pío, con diadema y hacia la derecha.

REV. / MENE $\Lambda$ AEITH $\Xi ; \Lambda \mathrm{H}$

Iconográficamente las monedas presentan en su reverso a un Harpócrates de perfil, situado hacia el lado izquierdo, con el dedo índice de la mano derecha situado en el borde de la boca. Con el brazo izquierdo porta una cornucopia, otro de sus rasgos característicos, y como ya dije antes, su mitad inferior corresponde al cuerpo de un cocodrilo. Esos son sus atributos generales, como muestra la Fig. 1, aunque pueden darse ligeras variaciones (presencia de altar o una estrella sobre su cabeza).

9 Sobre el nomo Menelaita Diod. Sic. XX, 21-53, Plut. Demet. 15-17 y Plin. HN, II. Este nomo tendría como capital a la ciudad de Canopo, en el delta del Nilo, la cual recibe el nombre del timonel de Menelao. Cf. Plin. HN, V, 128 y Str. XVII, 17, este último señala que el nombre se debe al hermano del primer Ptolomeo y no al héroe «como algunos escritores arguyen, incluído Artemidoro». Por este hecho, a esta peculiar versión de Harpócrates con mitad inferior de cocodrilo, se le suele conocer por los especialistas como Harpócrates de Canopo, cf. Dattari 1901, Milne 1971, Christiansen 1991, pass.

10 Vid. Emmet 2001, n. ${ }^{\circ}$ 500, Dattari 1901, n. ${ }^{\circ} 6.315$.

11 Imagen procedente del catálogo de la exposición Égypte Romaine. L" Autre Égypte, Marsella, 1997, pp. 89-90. 

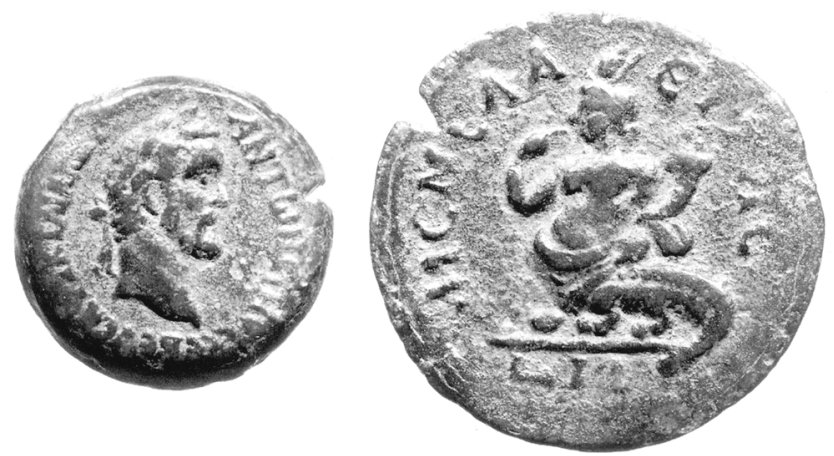

Fig. 1.

Esta misma disposición la encontramos en época trajanea, como así muestra el catálogo Milne, números 612b, 657-661 y en otras emisiones de Antonino Pío ${ }^{12}$.

Son escasos los paralelismos de este tipo de Horus-niño encontrados en otros soportes, destacando sólo un par de ejemplos. El primero se refiere a una gema mágica ${ }^{13}$ (Fig. 2), la cual presenta esta misma tipología de Harpócrates-Sobek, situado sobre un altar, con disco solar sobre la cabeza y mitad inferior de cocodrilo,

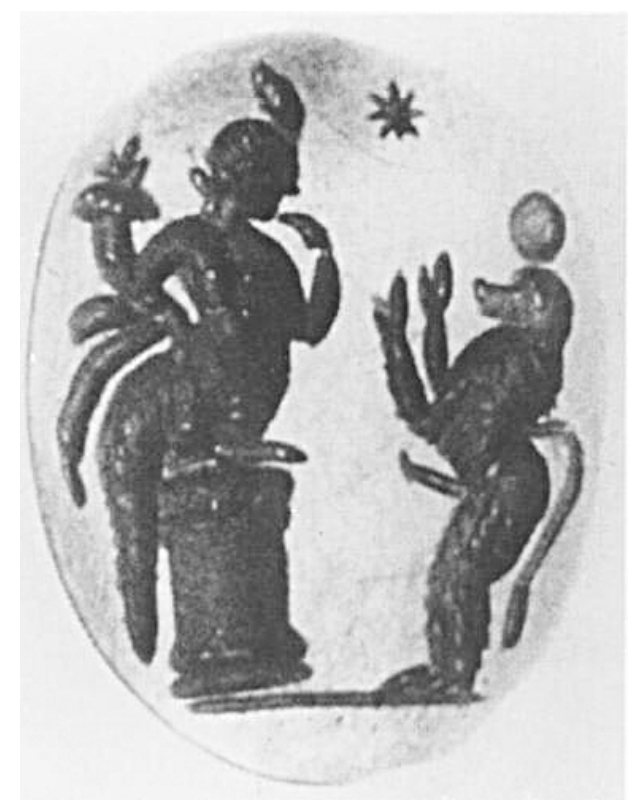

Fig. 2.

12 Milne 1971, n.․ 1797-1799 y 1829a.

13 LIMC IV (1988), vol. 1, p. 431, no. 223; vol. 2, p. 252, fig. 223. 
dedo índice en la boca, cornucopia y situado ante un cinocéfalo. La única diferencia, considerable por otro lado, es que presenta unas peculiares características itifálicas, dado que la gema estaba destinada a potenciar la fertilidad.

Por otro lado presento una estatua de bronce ${ }^{14}$ (Fig. 3), curiosamente fechada en época antonina, siglo II d.C., que vuelve a presentar los mismo rasgos, es decir, un Harpócrates con mitad inferior en forma de cocodrilo, cornucopia y disco solar sobre la cabeza, lo que lleva a pensar que en ese tránsito entre el primer y el segundo siglo de nuestra era, y más especialmente en la primera mitad de éste, se produjo el momento más álgido para la representación de esta tipología de Harpócrates, ya que ni antes ni después será recreada con tanta frecuencia, permitiéndonos centrar esta franja temporal como cúspide de esta manifestación religiosa, propiciada por otro lado, por el enorme sincretismo que dominaba en todo el imperio, y más concretamente en Alejandría, metrópolis multicultural por excelencia.

Es por todos sabido la importancia que ostentaba Horus en el panteón egipcio, como vengador de su padre Osiris y como representante de los poderes solares en el mundo de los vivos. Él era el patrón de la monarquía, una potente divinidad encargada de defender el Bien ante su tío y enemigo Set, asesino de su padre. La versión de Horus-infante es un producto de las últimas dinastías egipcias y principalmente del mundo helenístico, remitiendo a las fuerzas escondidas en la etapa infantil. Es decir, al igual que otros niños divinos (Dionisos, Hermes, Moisés), Harpócrates ( $h r-p 3-h r d=$ «Har-pe-chrot»= Horus-niño) se erige como símbolo de lo juvenil y vigoroso. Uno de sus aspectos fundamentales es su carácter de futuro. El

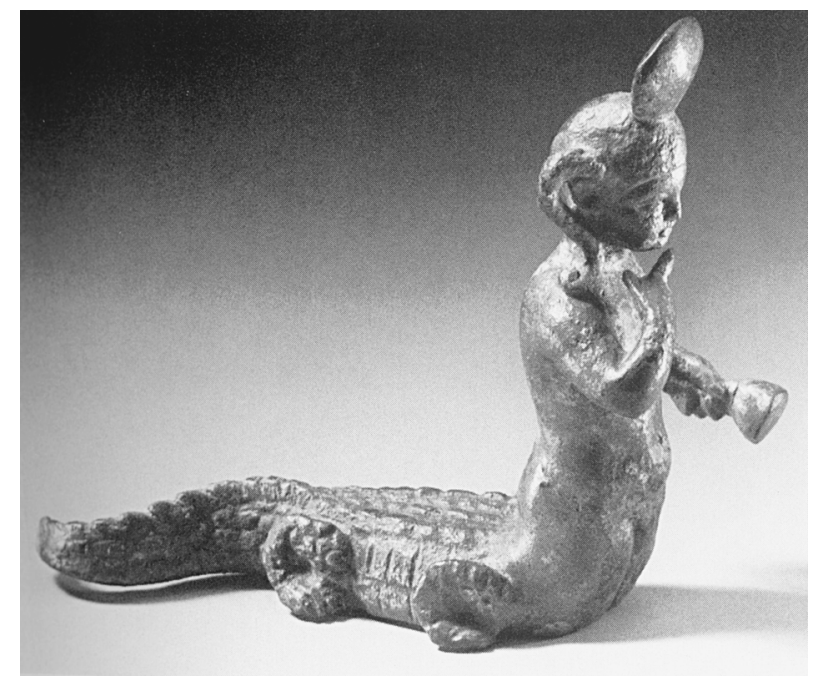

Fig. 3.

${ }_{14}$ LIMC IV (1988), vol. 1 p. 428; vol. 2 p. 249, fig. no. 181. 
niño, como dice C. G. Jung, «es futuro en potencia» ${ }^{15}$. En el caso de Harpócrates se presenta además como dominador de las alimañas, de todos los peligros que pueden acechar en el desierto, el reino de Set ${ }^{16}$.

Precisamente ese carácter de feliz porvenir, de futuro radiante, está en conexión con el tema de la cornucopia, por ser éste un elemento que simboliza la riqueza y la abundancia, fácilmente asociable a la persona del emperador. Elemento que por otro lado porta Isis, madre de Harpócrates, principalmente cuando aparece bajo la forma de la diosa serpiente Renenutet, es decir, como Isis-Thermouthis en su acepción griega ${ }^{17}$. Desde mi punto de vista es imprescindible el estudio de esta Isis-Thermouthis, representada con la mitad inferior de serpiente, para la comprensión del Harpócrates-Sobek que aquí se estudia. Esta advocación de Isis se erigía como protectora del faraón, como diosa agraria dispensadora de fertilidad y fecundidad, apareciendo ligada en el templo de Madinet Madi ${ }^{18}$, de nuevo en el delta, junto al dios cocodrilo Sokonopis, considerado también éste como dador de riqueza y prosperidad, y junto a Horus. En definitiva, una Isis con cuerpo de serpiente junto a un dios cocodrilo, dispensadores ambos de riquezas, constituyen un conjunto lógico para entender al posterior Harpócrates-Sobek, también concebido como dador de riquezas. Incluso en una imagen procedente del Museo de El Cairo se observa a Harpócrates situado entre Isis-Thermouthis y Sérapis-Agathodaimon, ambos con la mitad inferior del cuerpo en forma de reptil ${ }^{19}$.

Del resto de atributos que caracterizan a este dios hay dos que siguen creando discusión entre los estudiosos. Por un lado se sitúa el polémico gesto del dedo índice en la boca. Si bien para unos es simplemente un gesto que utilizaban los egipcios para remarcar la infancia, para otros, como es el caso de Jaime Alvar, el

15 Sobre las cualidades divinas del niño, principalmente en la mitología greco-romana, resulta imprescindible el texto de K. Kérenyi y C. G. Jung, Essays on a science of mythology. The myth of the divine child and the mysteries of Eleusis. Bollingen Series XXII, Princeton, 1973.

16 Sobre este control del mal son elocuentes la multitud de estelas mágicas (cippi) que presentan a Horus-niño reposando sobre un par de cocodrilos mientras domina con sus manos diferentes alimañas. Van acompañadas por textos mágicos de carácter apotropaico y profiláctico, presentando casi todas una tipología formal estándar que se sustancia de forma modélica en la llamada estela «Metternich». Sobre esta famosa estela destacan: C. E. Sander-Hansen, «Die Texte der Metternich-Stele «, Analecta Aegyptiaca 7 (1956), pp. 2-76; N. E. Scott, «The Metternich Stela», BMMA 9 (1950-1951), pp. 201-217; H. Sternberg El-Hotabi, Die Götterdarstellungen der Metternichstele. Ein Neuansatz zu ihrer Interpretation als Elemente eines Kontinuitätsmodells, GM 97 (1987), pp. 25-70; De forma más general sobre los cipos de Horus vid. H. Sternberg El-Hotabi, Untersuchungen zur Überlieferungsgeschichte der Horusstelen, Wiesbaden, 1999.

17 Para el estudio de Isis Thermouthis vid. F. Dunand Le culte d'lsis dans le bassin oriental de la Méditerranée. Le culte d'Isis et des Ptolémées, vol. I, Leiden, 1973 y «Les représentations de l'agathodémon. À propos de quelques bas-reliefs du musée d'Alexandrie», BIFAO 67 (1969), pp. 9-48. Cf. V. Tran Tam Tinh, «Etats des études iconographiques relatives à Isis, Sérapis et Sunnaoi Theoi», ANRW, 17.3 (1984), pp. 1710-1738.

18 Pequeño templo de planta rectangular situado al suroeste de El Fayum y erigido en principio por Amenhemat III y IV, ambos de la XII dinastía. Fue ampliado en la XIX dinastía y en época ptolemaica. Estaba consagrado a Isis identificada con la diosa de la recolección Ermouthis-Renenoutet y a una forma de dios cocodrilo, llamado Sokonopis. Vid. A. Vogliano, Secondo rapporto degli scavi condotti dalla Missione archeologica d'Egitto della R. Università di Milano nella zona di Madinet Madi, Milán, 1937.

19 Museo del Cairo, n. ${ }^{\circ}$ Inv. 26422. 
«dedo indica el precepto del silencio» ${ }^{20}$, el cual vendría puesto en relación con los misterios isíacos, donde el nuevo iniciado debe demostrar sus facultades como tal a través de la máxima discreción, debiendo saber guardar el secreto de la iniciación, tal y como ocurre en los misterios de Eleusis. Ese silencio vendría a ser un preludio de apertura a la revelación, la apertura de un nuevo camino de salvación, el cual se representa en la forma del niño divino. Éste representa al nuevo ser regenerado, el cual ha asistido a su propio renacimiento en vida tras una muerte figurada.

En este sentido los romanos interpretaron este gesto como un signo de discreción, poniendo estatuas de este dios en la puerta de los templos, como forma de remarcar la actitud que el hombre debía de mostrar ante los dioses ${ }^{21}$. Algo que refuerza aún más esta idea es el hecho de que ese gesto, el de poner el dedo en la boca, es el que utilizó Isis para criar a Horus-niño, en lugar de amamantarlo; del mismo modo, en el relato que nos legó Plutarco acerca del mito osiríaco, se puede observar como se repite el gesto por parte de Isis a la hora de criar al hijo de los reyes de Biblos, Melcandro y Astarté, en el momento en el que anda buscando a su esposo perdido ${ }^{22}$, poniendo el dedo en su boca, en lugar del pecho ${ }^{23}$.

El otro rasgo, de hecho, el más característico de estas monedas, es la mitad inferior en forma de cocodrilo que presenta Harpócrates ${ }^{24}$.

Al margen de la importante relación existente entre esta representación del niño divino egipcio y las representaciones serpentiformes de Isis-Thermouthis, este animal es visto de forma bien distinta en función de la región de Egipto en la que nos situemos. Ya Claudio Eliano nos hace eco de esta dicotomía en su Historia Animalium ${ }^{25}$, cuando pone como ejemplo el diferente trato que sufre este animal en dos nomoi bien distintos como son el Ombita y el Apolonopolita. Si los primeros lo veneran y lo tienen como un animal divino, los habitantes de Apolonópolis lo detestan, cazándolo y ultrajándolo cada vez que pueden, ya que lo ponen en relación con Tifón (Set).

20 J. Alvar, Los Misterios. Religiones orientales en el imperio romano, Barcelona, 2002.

21 Algunas fuentes al respecto son bastante elocuentes sobre la relación entre el gesto del silencio y Harpócrates, así en Varr., leng. lat., 1.1, 5, 10, en el momento de comenzar a hablar de los dioses, comparando a los egipcios con los romanos observa que «estos dioses son los mismos los de Egipto, Sérapis e Isis, aunque Harpócrates me hace señas con el dedo de que me calle...»; por otro lado, en Ov. met., IX, 692, se dice «y el que reprime la voz y aconseja con los dedos guardar silencio»; y en Cat. 74,4, se cuenta como se convirtió a un hombre, al parecer demasiado charlatán, en un Harpócrates, es decir, en alguien más discreto, «Gelio había oído decir que su tío solía pelearse con quien hablaba de goces amorosos o con quien los disfrutaba. Para que esto no le ocurriera perdió a la propia mujer de su tío y convirtió a su tío en un Harpócrates. Consiguió su objetivo. Pues, aunque ahora se la haga chupar a su propio tío, no dirá palabra».

22 Este pasaje guarda una estrecha relación con el Himno homérico a Deméter, 213, 231-238, en el que la diosa también intenta criar al hijo del rey Keleo y su esposa Metanyra con el fin de hacerlo inmortal, mientras anda buscando, en este caso, a su hija Perséfone. La identificación entre Isis y Deméter se establece ya desde Heródoto, II, 59, 2. Cf. Ov. met. IX, 685 ss.

23 Plut. De Is. et Os., 16C.

24 No se trata de la primera vez que encontramos a Horus asimilado a Sobek, ya que se sabe por

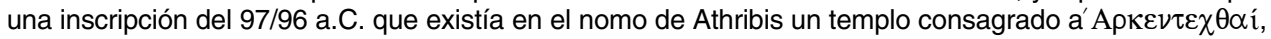
es decir, Horus- Khentekhtai, asimilado a un antiguo dios cocodrilo. Cito a Dunand, supra n. 17.

${ }^{25}$ Eliano, Hist. Anim., X, 21. Cf. Arist. HA, II, 10 para la descripción de este animal. 
Ambivalencia que también se remarca por el hecho de ser asimilado como Sobek (Soukhos en griego) al dios solar, es decir, Horus, por ser entre otras cosas recolector de los miembros descuartizados de su padre, Osiris, y por otro por ser un animal tifoniano, como Southok-Set.

Destaca así su carácter bipolar, por un lado dada su agresividad y poder destructor, representado en el sistema jeroglífico por la furia y la maldad, y por otro por un aspecto más solar y relacionado con el tema de la fecundidad y de la fuerza. Es por tanto usual encontrar ambos perfiles de este animal en función de la región en la que nos situemos ${ }^{26}$. Debido a esto y a que en una ciudad como Cocodrilópolis, capital de El Fayum, en el delta y por tanto muy próxima al nomo Menelaita, estuviera consagrada a este animal, no es de extrañar que se produzcan asimilaciones entre ambas regiones, conjugando en un mismo ser a Harpócrates y al divino reptil. Pero se pueden establecer algunas otras vinculaciones más sugerentes. En primer lugar un breve pasaje del De Iside et Osiride de Plutarco llama la atención:

De Osiris, unido a ella después de la muerte, Isis engendró a Harpócrates, nacido prematuramente y con las extremidades inferiores debilitadas.

De Is. et Os. 19D.

Este pasaje se puede pasar sin más, ya que todos los niños nacen con las extremidades inferiores debilitadas, pero en el caso de la representación de una divinidad potente y juvenil como es el caso de Harpócrates, emblema de juventud y vigor, no sería muy lógico representarlo así, sería más apropiado potenciar la parte más débil de su cuerpo, sustituyendo en su iconografía las frágiles piernas por el resistente y peligroso cuerpo del cocodrilo ${ }^{27}$.

Por otro lado en los textos antiguos se resaltan continuamente una serie de atributos divinos que sólo ostenta este animal y que le pondría en relación directa con la divinidad. De esta forma tendría más sentido el sincretismo Harpócrates-Sobek que aquí se discute ya que ambos compartirían comportamientos, aportando cierta lógica a sus rasgos iconográficos. En primer lugar destaca el carácter silencioso de este animal ${ }^{28}$, un atributo de carácter divino que lo pondría en relación directa con el tema del dedo en la boca antes tratado y por tanto con los misterios isíacos tan de moda en época romana. Ello se debe al pensamiento que se tenía en la antigüedad de que el cocodrilo no poseía lengua ${ }^{29}$ (que sí la tiene pero es minúscula y está situada pegada al paladar), algo que se tenía como una imagen de

${ }^{26}$ Así lo señala por otro lado Heródoto, II, 68-69 al decir que «para algunos egipcios los cocodrilos son sagrados, pero no para otros, que los tratan como enemigos».

27 J. Hani, en La religion égyptienne dans la pensée de Plutarque, París, 1976, p. 80 ss., rebate este pasaje arguyendo que se trata de un error griego, ya que tal afirmación no aparece en ningún texto egipcio. En cualquier caso no afecta al discurso aquí expuesto ya que el propio Harpócrates-Sobek que trato aquí es también un producto creado en ámbito greco-romano, no egipcio, coincidiendo ambos supuestos en el espacio y en el tiempo.

28 Plut. De Is. et Os., 76; Hdt. II, 68 ss.; Eliano, Hist. Anim., II, 33. Cf. Hani 1976, op. cit.

29 Plut. De Is. et Os. 71-76. 
Dios, el cual no tiene necesidad de hablar para hacerse entender o manifestarse (de nuevo el precepto del silencio tan requerido en las religiones mistéricas y de iniciación). El propio Eurípides en sus Troyanas (887-888) dice de este animal que «avanzando por camino silencioso, conduce de acuerdo con la equidad todas las cosas mortales" rasgo que podría aplicarse con todas sus connotaciones a las dimensiones que ocupa Horus, guía de los hombres en este mundo. Otro de los atributos sería la capacidad de ver sin ser visto, facultad desarrollada por su carácter depredador, que le permite tener una membrana lisa y transparente en su aparato ocular, pero que a la vez, en una esfera divina, constituye el privilegio del primero de los dioses ${ }^{30}$. En resumen, es capaz de manifestarse sin hablar, y de ver sin que lo vean, algo propio de un dios. Jean Hani, además de estos dos atributos señala otros dos que también hablarían del perfil divino del animal ${ }^{31}$, por un lado la presciencia que se manifiesta en la manera de moverse y situarse. Esta facultad se pondría en relación con el carácter profético, del que todo lo ve, y que en el pensamiento egipcio siempre estaba vinculado al ojo de Horus (udjat), símbolo mágico por excelencia. Por otro lado se situaría la armonía con el ritmo temporal simbolizado por el número 60 , que se repite continuamente en la naturaleza del animal y que según Plutarco, es la primera unidad de medida para los astrónomos egipcios ${ }^{32}$.

En definitiva, destacando estos atributos sólo pretendo plantear la posibilidad de que ese animal no fue elegido al azar para utilizarlo como complemento de Harpócrates, sino que respondía a un proceso mental lógico, por muy sincrético que pudiera ser el proceso. Las características y la tradición del animal son perfectamente adaptables a la naturaleza y características de Harpócrates, siendo muchos rasgos los que los ponen en estrecha relación, justificando de esta forma la peculiar iconografía que aparece en las monedas antes citadas. Los rasgos divinos del animal, su asociación con Sobek, y las asociaciones iconográficas que existen con Isis-Thermouthis, Sokonopis y Harpócrates en Madinet Madi darían de esta forma sentido a la iconografía que se presenta en estas monedas.

Harpócrates se erige así como un efectivo modelo de poder, impregnado de un futuro fértil y dichoso, a la vez que ostenta un carácter poderoso, dado el propio mito que le da sentido, y la propia asimilación que sufre, o disfruta, con un animal tan peligroso, adorado y divino como lo era el cocodrilo. En definitiva, viene a representar las propias cualidades del emperador.

\section{RELIGIÓN, PODER Y PROPAGANDA POLÍTICA A TRAVÉS DE LAS ACUÑACIONES MONETALES}

Al mismo tiempo que se da una conjunción iconográfica entre dos símbolos como son el cocodrilo y Harpócrates, se produce una segunda asimilación cuando esta representación religiosa se pone junto a la efigie del emperador en las mo-

\footnotetext{
30 Plut. De ls. et Os., 75.

31 Hani 1976, p. 432.

32 Plut. De Is. et Os., 75C, Cf. Eliano, Hist. Anim., X, 21.
} 
nedas. En este caso se asimilan ambas figuras, trasvasándose las peculiaridades del dios (carácter de futuro, juventud, vigor, fertilidad, en definitiva, estabilidad y poder) al propio emperador. En este sentido, como señala Díez de Velasco, «el orden político y el orden cósmico resultan indisociables» ${ }^{33}$, siendo el regente el que mantiene el equilibrio entre ambos, ya que es él el que toma las decisiones, el que ostenta el poder fáctico. De la religión saca precisamente una de las mayores bazas para obtener el máximo control. Díez de Velasco, en su excelente artículo remata, «política y religión resultan una misma cosa, la laboriosa ordenación y estabilización del mundo ${ }^{34}$

Si para el habitante del nomo Menelaita, y en general del Egipto romano, Harpócrates representaba todas esas cualidades, en el momento en el que se plasman en las monedas junto al emperador, este se ve asimilado al dios. El propio emperador se diviniza, pasando a ser respetado y adorado por todo el pueblo. Es sin duda una efectiva estrategia de propaganda y control político cuando de lo que se trataba era de gobernar de forma estable un imperio como el romano del siglo II d.C. Con este acercamiento religioso se conseguía el control de las fronteras más lejanas. El emperador recordaba, a través de su efigie, la eterna presencia del poder romano. Constituye el instrumento de propaganda más eficaz. Si lo más poderoso, temible y respetable que se pueda imaginar cualquier pueblo es precisamente un dios, la mejor manera para el emperador de hacer valer su hegemonía era la de identificarse con la divinidad, la de hacerse él mismo un dios, atribuirse un origen divino. De esta manera, el emperador, para asentar su autoridad realizaba diferentes estrategias propagandísticas. S. Skowronek establece en este sentido seis categorías $\left.{ }^{35}: 1\right)$ deificar a sus predecesores, de esta forma justificaban su reinado, tenían derecho divino; 2) aparecer como el favorito de un dios que le da protección particular; 3) recibir los atributos y títulos del dios, asumiendo él mismo ser la encarnación de ese dios; 4) proclamar al dios como su padre; 5) convertirse en «synnaos theos»; y 6) permitir que sean adorados su "genio" y sus cualidades divinas.

No es difícil por tanto concluir que las monedas imperiales del primer y segundo siglo d.C. a las que estoy haciendo referencia en este artículo, reflejan en su iconografía e inscripciones los elementos de culto al gobernador antes citados. En ese sentido, cualquier tipo de manifestación artística, incluidas las monedas, eran hechas con un fin muy preciso, la de servir al soberano en el asentamiento de su poder.

Al mismo tiempo estas monedas nomaicas constituían la conmemoración de la autonomía política de los diferentes nomos. Aunque estuvieran supeditados a la ley romana, de alguna forma, al ser representados de manera independiente en las monedas, con los atributos de cada uno, se valoraba la propia idiosincrasia que re-

${ }^{33}$ F. Díez de Velasco, «Religión, poder político y propaganda: reflexiones teóricas y metodológicas», en F. Marcos Simón, F. Pina Polo, J. Remesal Rodríguez (eds.), Religión y propaganda política en el mundo romano, Barcelona, 2004, pp. 13-25.

34 Ibid. p. 17.

35 S. Skowronek On the problems of the alexandrian mint, Varsovia, 1967, pp. 69-78. 
gía cada región. El emperador, a través de estas realizaciones, se entremetía en los estratos más queridos y característicos de cada zona. Suponía otra forma de conquista, una segunda ocupación del país después de la estrictamente territorial, aquella que se refería a las tradiciones y las creencias de un país. Esta no se hacía con las armas al uso, sino a través de un sutil proceso de asimilación y respeto por la tradición.

La moneda como instrumento y representación del poder era fiel reflejo del pensamiento religioso romano, en el que había cabida para todos los dioses y manifestaciones divinas, incluso para las de tipo «subprovincial», como es el caso de las alejandrinas. Eso sí, siempre y cuando se respetara, asumiera y afirmara que el máximo poder y la máxima autoridad eran potestad del emperador.

Se equiparaba así el poder extranjero con el culto más ancestral. Con esta equiparación el poder del emperador se afianzaba y elevaba a una categoría divina, como un nuevo faraón. Como bien indica Knippschild, el poder romano «se valía de representaciones visuales para proyectar ideas colectivas ${ }^{36}$. De esta forma, con algo muy concreto y con un formato sencillo y efectivo como era el de las monedas, se lograba penetrar en las creencias más antiguas de un país.

En conclusión, es de destacar la enorme riqueza de significados que albergaban las acuñaciones monetales. La moneda, no era sólo una moneda. Al margen de su utilidad práctica como medio de intercambio comercial y económico suponía también un potente elemento de propaganda política en los que se combinaban de forma prodigiosa los poderes políticos, a través de la efigie del emperador y los religiosos, a través de las diferentes divinidades representadas en sus reversos. Las monedas eran poder en esencia, tanto por su valor intrínseco como extrínseco. Eran objetos de valor, tanto por sus cualidades económicas, como por sus cualidades representativas de los poderes fácticos y religiosos.

Al mismo tiempo suponen un excelente motivo para estudiar las peculiares variantes iconográficas de los dioses representados, para cerciorarnos sobre los dioses tutelares de cada nomo o para establecer la relativa importancia de unas poblaciones sobre otras.

En este sentido, las representaciones del poder político y religioso, son más que nunca, las dos caras de una misma moneda.

36 S. Knipschild, «¡Abajo el tirano! Destrucción de símbolos imperiales como representación del cambio de poder», en H. D. Heimann, S. Knippschild, y V. Mínguez (eds.), Ceremoniales, ritos y representación del poder, Castellón, 2004. pp. 57-88. 